\title{
Effects of valsartan and amlodipine on cardiorenal protection in Japanese hypertensive patients: the Valsartan Amlodipine Randomized Trial
}

\author{
Hiroya Narumi ${ }^{1}$, Hiroyuki Takano ${ }^{1}$, Satoshi Shindo, Miwa Fujita, Hiroshi Mizuma, Yoichi Kuwabara \\ and Issei Komuro, on behalf of the VART Investigators
}

The Valsartan Amlodipine Randomized Trial, a multicenter, prospective, randomized, open-labeled, blinded-end point trial, was designed to compare the beneficial effects of the angiotensin II receptor blocker valsartan and the calcium channel blocker amlodipine on cardiovascular events in Japanese essential hypertensive patients. The primary end point was a composite of all-cause death, sudden death, cerebrovascular death, cardiac events, vascular events and renal events. The secondary endpoints were effects on left ventricular hypertrophy, cardiac sympathetic nerve activity and renal function. A total of 1021 patients were enrolled in the present trial. The mean follow-up period was 3.4 years. There were no significant differences in blood pressure (BP) levels between the valsartan group and the amlodipine group throughout the trial. There was no significant difference in the primary endpoint between the two groups (hazard ratio: 1.0, $P=0.843$ ). No difference in any event category of the primary endpoint was noted for either group. However, we observed a significant reduction of left ventricular mass index, as determined by echocardiography, in the valsartan group compared with the amlodipine group. We also observed a significant decrease in cardiac sympathetic nerve activity in the valsartan group but not in the amlodipine group. Moreover, there was a significant reduction in the urinary albumin to creatinine ratio in the valsartan group but not in the amlodipine group. Therefore, although BP levels were well controlled and remained equal in the two groups, valsartan had more protective effects on the heart and kidney than amlodipine in Japanese hypertensive patients.

Hypertension Research (2011) 34, 62-69; doi:10.1038/hr.2010.186; published online 7 October 2010

Keywords: angiotensin II receptor blocker; calcium channel blocker; clinical trial; left ventricular hypertrophy

\section{INTRODUCTION}

Hypertension is the most common disease in Japan. Antihypertensive agents, which inhibit the renin-angiotensin system, have been known to have beneficial effects on cardiovascular and renal functions that extend beyond their reduction of blood pressure (BP). Many clinical randomized trials have shown the beneficial effects of angiotensin II receptor blockers (ARBs) on cardiovascular mortality and morbidity in patients with hypertension, heart failure, stroke or end-stage renal disease. ${ }^{1-6}$ ARBs and calcium channel blockers (CCBs) have effective BP-lowering effects and are widely used in Japan. Although the beneficial effects of ARBs on high-risk hypertensive patients in Japan were recently demonstrated, few trials have been performed to compare the efficacy of ARBs compared with CCBs in preventing cardiovascular events. It is important to investigate the differences in effects of these antihypertensive agents to determine the optimal approach to treatment.
The Valsartan Antihypertensive Long-term Use Evaluation (VALUE) trial was designed to investigate whether valsartan could reduce cardiac morbidity and mortality more effectively than amlodipine in hypertensive patients at high cardiovascular risk who were treated with the same approach to BP control in Europe and the United States. ${ }^{7}$ BP was reduced by both treatments, but the effects of the amlodipine-based regimen were more pronounced, especially in the early period. Furthermore, there was no significant difference between the two groups in the primary composite endpoint. It is possible that an unequal reduction of BP in both groups obscured the favorable effects of valsartan. Owing to the differential response to therapeutic agents and the variation in event rates of cardiovascular disease between Asian and Western populations, the data from trials performed in other countries are not necessarily applicable to Japanese patients. In this study, we aimed to compare the beneficial effects related to cardiovascular events exerted by valsartan compared with amlodipine in Japanese low-risk patients with mild to moderate hypertension.

Department of Cardiovascular Science and Medicine, Chiba University Graduate School of Medicine, Chiba, Japan

Correspondence: Dr I Komuro, Department of Cardiovascular Science and Medicine, Chiba University Graduate School of Medicine, 1-8-1 Inohana, Chuo-ku, Chiba 260-8670,

Japan.

E-mail: komuro-tky@umin.ac.jp

1 These authors contributed equally to this work.

Received 7 June 2010; revised and accepted 1 July 2010; published online 7 October 2010 


\section{METHODS}

\section{Study population}

Inclusion criteria in the Valsartan Amlodipine Randomized Trial (VART) included age $\geqslant 30$ years and recent diagnosis of hypertension (systolic $\geqslant 140 \mathrm{~mm} \mathrm{Hg}$ or diastolic BP $\geqslant 90 \mathrm{~mm} \mathrm{Hg}$, with the patient in a sitting position at a clinic) or previous treatment with antihypertensive agents. The exclusion criteria were secondary hypertension, serious valvular disease or congenital heart disease requiring operative treatment, hypertrophic or dilated cardiomyopathy, percutaneous transluminal coronary angioplasty or coronary artery bypass graft within 6 months, stroke within the preceding 3 months and serious renal dysfunction (serum creatinine $>3 \mathrm{mg}$ per $100 \mathrm{ml}$ ). The detailed inclusion criteria and exclusion criteria have been described previously. ${ }^{8}$ We enrolled 1021 patients with mild to moderate hypertension between July 2002 and February 2006. The VART was closed on March 2009.

\section{Study design}

The VART was a multicenter, prospective, randomized, open-labeled, blindedend point (PROBE) design. The trial sought to compare two antihypertensive treatment strategies involving 92 medical facilities in Japan. The ethics committee at Chiba University Graduate School of Medicine approved the VART protocol, which adhered to the principles of the Declaration of Helsinki. The rationale and design of the VART have been published elsewhere. ${ }^{8}$ The random assignment of patients, data entry and data collection were performed at the homepage originally produced for the VART, and the participants were assigned randomly to either the valsartan group or the amlodipine group with the minimization ${ }^{8}$ method after informed consent was obtained. The BP of each patient was measured with the individual in a sitting position with the use of a validated mercury sphygmomanometer at a clinic. The mean of three measurements was calculated and recorded. We aimed to control BP to $<140 /$ $90 \mathrm{~mm} \mathrm{Hg}$ in both treatment groups. The first dose of valsartan or amlodipine was 80 or $5 \mathrm{mg}$ per day, respectively. When the patient's BP did not reach the BP target, the doses were increased to 160 or $10 \mathrm{mg}$ per day, respectively. $\alpha$-Blockers, $\beta$-blockers or diuretics were then added when necessary, as described previously. ${ }^{8}$ If the patients were already receiving antihypertensive treatment before enrollment, their medication was changed to either $80 \mathrm{mg}$ per day valsartan or $5 \mathrm{mg}$ per day amlodipine without a run-in period. This trial has been registered at http://www.umin.ac.jp/ctr/index.htm (identifier C000000074).

\section{Outcome measurements}

The primary endpoint was a composite of all-cause death, sudden death, cerebrovascular events (new occurrence or recurrence of a stroke or transient ischemic attack), cardiac events (new occurrence or recurrence of acute myocardial infarction or angina pectoris, or new occurrence or exacerbation of heart failure), vascular events (dissecting aneurysm of the aorta or hospitalization due to arteriosclerotic occlusion of a peripheral artery) and renal events (doubling of serum creatinine or end-stage renal disease), as described previously. ${ }^{8}$ The secondary endpoints were effects on left ventricular hypertrophy (LVH), cardiac sympathetic nerve activity, blood norepinephrine level, renal function and incidence of recent-onset diabetes, as described previously. ${ }^{8}$ After patient enrollment, routine laboratory tests were performed every 6 months. Plasma norepinephrine concentration and urinary albumin to creatinine ratio (UACR) were also measured every 12 months. Echocardiography was performed to examine the change in left ventricular mass index (LVMI) every 12 months. Left ventricular mass was measured using M-mode guided echocardiography, according to the formula introduced by Devereux et al. ${ }^{9}$ : $0.80 \times\{1.04 \times[$ (septal thickness $+\mathrm{LV}$ internal diameter $\times$ posterior wall thickness $\left.\left.)^{3}-(\mathrm{LV} \text { internal diameter })^{3}\right]\right\}+0.6 \mathrm{~g}$; LVMI was calculated with body surface area correction. ${ }^{123}$ I-metaiodobenzylguanidine (MIBG) cardiac imaging was performed at the participating medical institutes. Recent-onset diabetes was diagnosed if treatment with hypoglycemic agents had been initiated and/or the plasma glycosylated hemoglobin concentration exceeded $6.5 \%$ during the trial.

\section{Statistical analysis}

On the basis of previous studies, the incidence of cardiovascular events with amlodipine was estimated to be $5 \% .^{10,11}$ We estimated that the incidence of cardiovascular events would be $40 \%$ lower in patients treated with valsartan than in those treated with amlodipine. Therefore, 1280 patients would be needed in each group (2560 in total), with a two-sided $\alpha$-level of 0.05 and $90 \%$ power. Assuming a dropout rate of $15 \%, 3000$ patients (1500 in each group) were considered to be required for the study. All primary analyses were performed utilizing an intention-to-treat approach.

We estimated hazard ratios and $95 \%$ confidence intervals (CI) to compare the treatment groups. Hazard ratios were calculated and adjusted for age, gender, smoking, diabetes and hypercholesterolemia with Cox's proportional hazard model. Statistical analysis of event rates over time was presented as Kaplan-Meier plots for specific treatment arms. The differences in the frequency of adverse events were analyzed with $\chi^{2}$-tests. To analyze changes in LVMI, we used repeated-measurement two-way analysis of variance; $P$-values were computed by the Newman-Keuls test for intergroup comparisons at the end of the trial. Statistical analysis of the results to evaluate changes in plasma norepinephrine concentration, the heart to mediastinum (H/M) ratio on delayed imaging of ${ }^{123} \mathrm{I}-\mathrm{MIBG}$ and UACR were estimated with regression model analysis. All the statistical tests were two sided, with an $\alpha$-level of $0.05 \%$.

\section{Study management}

Data related to the primary and secondary endpoints and adverse events were collected at various time points, and interim analyses were performed every year after the initiation of the study. An independent endpoint committee, which was blinded to any information related to group allocations, evaluated each event and classified the results. An independent data and safety monitoring board reviewed all reports from the endpoint committee and advised the designers of the trial with regard to safety. A steering committee was responsible for the study design and scientific execution of the study. Data analyses were performed in the Department of Clinical Epidemiology, Osaka City University Graduate School, which was independent of the group that implemented the study.

\section{RESULTS}

\section{Baseline characteristics}

A total of 1021 patients were enrolled in the VART. Of those patients, 510 patients were assigned to the valsartan group, and 511 patients were assigned to the amlodipine group. As shown in Figure 1, 1021 randomly assigned patients were included in the analysis, and 16 patients $(1.6 \%)$ were lost to follow-up. Table 1 shows the baseline characteristics of the patients. There were no significant differences between the two groups in baseline characteristics such as age, gender, body mass index, coronary artery disease, diabetes mellitus, hyperlipidemia, LVH and antihypertensive treatment before enrollment. Table 2 presents medications at baseline. There were no significant differences between the two groups in medications at baseline.

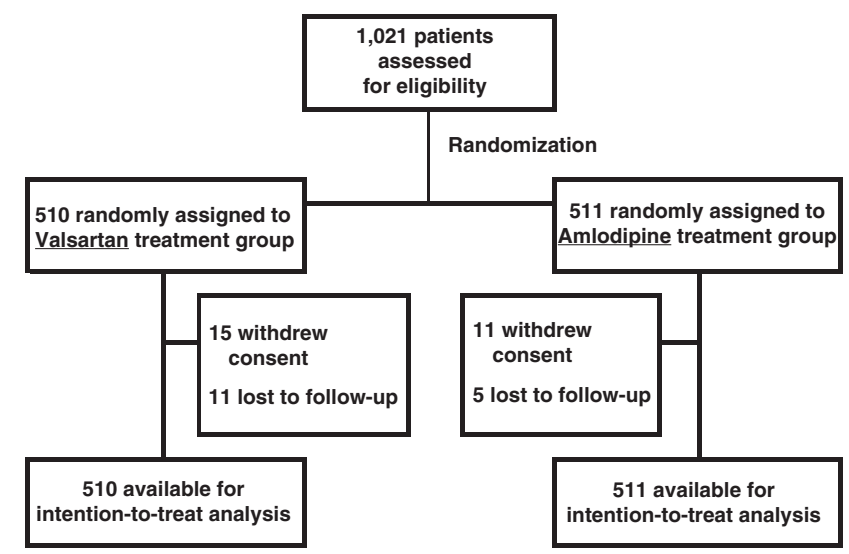

Figure 1 Trial profile. 
Table 1 Baseline characteristics of patients

\begin{tabular}{lcc}
\hline & $\begin{array}{c}\text { Valsartan } \\
(\mathrm{n}=510)\end{array}$ & $\begin{array}{c}\text { Amlodipine } \\
(\mathrm{n}=511)\end{array}$ \\
\hline Age (years) & $60 \pm 12$ & $60 \pm 11$ \\
Men & $290(56.9 \%)$ & $294(57.5 \%)$ \\
Body mass index & $25 \pm 4$ & $24 \pm 3$ \\
Current smoker & $108(21.2 \%)$ & $107(20.9 \%)$ \\
Coronary artery disease & $18(3.5 \%)$ & $17(3.3 \%)$ \\
Heart failure & $1(0.2 \%)$ & $7(1.4 \%)$ \\
Diabetes mellitus & $37(7.3 \%)$ & $46(9.0 \%)$ \\
Hyperlipidemia & $136(26.7 \%)$ & $145(28.4 \%)$ \\
Left ventricular hypertrophy & $117(22.9 \%)$ & $119(23.3 \%)$ \\
Antihypertensive treatment before enrollment & $235(46.1 \%)$ & $233(45.6 \%)$ \\
Systolic blood pressure $(\mathrm{mm} \mathrm{Hg})$ & $158 \pm 19$ & $158 \pm 18$ \\
Diastolic blood pressure $(\mathrm{mm} \mathrm{Hg})$ & $93 \pm 13$ & $94 \pm 13$ \\
Ejection fraction & $63 \pm 9$ & $63 \pm 9$ \\
HDL-cholesterol (mg per $100 \mathrm{ml})$ & $58 \pm 27$ & $58 \pm 16$ \\
LDL-cholesterol (mg per $100 \mathrm{ml})$ & $127 \pm 34$ & $124 \pm 33$ \\
Triglyceride (mg per $100 \mathrm{ml})$ & $139 \pm 103$ & $147 \pm 90$ \\
Fasting plasma glucose & $106 \pm 24$ & $107 \pm 25$ \\
HbAlc (\%) & $5.4 \pm 0.9$ & $5.4 \pm 1.2$ \\
Serum creatinine (mg per $100 \mathrm{ml})$ & $0.76 \pm 0.18$ & $0.76 \pm 0.21$ \\
\hline Abbevtions: & & \\
& & \\
& &
\end{tabular}

Abbreviations: HbAlc, hemoglobin Alc; HDL, high-density lipoprotein; LDL, low-density lipoprotein.

Values are number $(\%)$ or mean \pm s.d.

Table 2 Medication at baseline

\begin{tabular}{lcc}
\hline & $\begin{array}{c}\text { Valsartan } \\
(\mathrm{n}=510)(\%)\end{array}$ & $\begin{array}{c}\text { Amlodipine } \\
(\mathrm{n}=511)(\%)\end{array}$ \\
\hline ACE inhibitors & $29(6)$ & $22(4)$ \\
Calcium channel blockers & $138(27)$ & $135(26)$ \\
$\alpha$-Blockers & $4(1)$ & $7(1)$ \\
$\beta$-Blockers & $16(3)$ & $22(4)$ \\
Diuretics & $12(2)$ & $13(3)$ \\
ARBs & $47(9)$ & $51(10)$ \\
Statins & $56(11)$ & $50(10)$ \\
Fibrates & $8(2)$ & $4(1)$ \\
Oral hypoglycemic agents & $16(3)$ & $16(3)$ \\
Anticoagulation agents & $9(2)$ & $16(3)$ \\
\hline
\end{tabular}

Abbreviations: ACE, angiotensin-converting enzyme; ARBs, angiotensin II receptor blockers.

\section{Follow-up and adherence to treatment}

The mean follow-up period was 3.4 years. The study accumulated 3390 person-years of follow-up (1742 person-years and 1648 personyears for the valsartan- and the amlodipine-based regimens, respectively). During follow-up, it was determined that more than $99 \%$ of patients received the appropriate drugs. At the end of the trial, the percentages of the patients who received only valsartan or amlodipine were $69.2 \%$ in the valsartan-based regimen and $81.7 \%$ in the amlodipine-based regimen, respectively (Table 3). Additional treatments in both groups were mainly diuretics, $\beta$-blockers and $\alpha$-blockers. The average number of antihypertensive drugs taken during the study was slightly higher in the valsartan group than in the amlodipine group. The reported adverse events are summarized in Table 4. Few adverse events were recognized in either the valsartan group $(4.9 \%)$ or the amlodipine group (1.4\%).
Table 3 Ratios of the patients with monotherapy

\begin{tabular}{ccccc}
\hline $\begin{array}{c}6 \text { months } \\
(\%)\end{array}$ & $\begin{array}{c}12 \text { months } \\
(\%)\end{array}$ & $\begin{array}{c}24 \text { months } \\
(\%)\end{array}$ & $\begin{array}{c}36 \text { months } \\
(\%)\end{array}$ \\
\hline $\begin{array}{c}\text { Valsartan } \\
80 \mathrm{mg}\end{array}$ & 64.8 & 60.4 & 58.2 & 55.9 \\
$160 \mathrm{mg}$ & 12.9 & 13.1 & 9.7 & 13.3 \\
& & & & \\
Amlodipine & & & 68.3 & 70.4 \\
$5 \mathrm{mg}$ & 76.7 & 72.4 & 11.3 & 11.3 \\
$10 \mathrm{mg}$ & 11.8 & 9.7 & & \\
\hline
\end{tabular}

Table 4 Adverse effects

\begin{tabular}{lccc}
\hline & $\begin{array}{c}\text { Valsartan } \\
(\mathrm{n}=510) \text { number }\end{array}$ & $\begin{array}{c}\text { Amlodipine } \\
(\mathrm{n}=511) \text { number }\end{array}$ & \\
& $(\%)$ & $(\%)$ & P-value \\
\hline Dizziness & $4(0.8)$ & $2(0.4)$ & 0.41 \\
Headache & $4(0.8)$ & $0(0.0)$ & 0.05 \\
Drowsiness & $1(0.2)$ & $0(0.0)$ & 0.32 \\
Hot flash & $1(0.2)$ & $2(0.4)$ & 0.56 \\
Palpitations & $1(0.2)$ & $0(0.0)$ & 0.16 \\
Hypotemperature & $1(0.2)$ & $0(0.0)$ & 0.32 \\
Sweat & $1(0.2)$ & $0(0.0)$ & 0.32 \\
Edema & $1(0.2)$ & $3(0.6)$ & 0.32 \\
Hypotension & $0(0.0)$ & $0(0.0)$ & \\
Abdominal fullness & $1(0.2)$ & $0(0.0)$ & 0.32 \\
Gastrointestinal bleeding & $1(0.2)$ & $0(0.0)$ & 0.32 \\
Heart burn & $1(0.2)$ & $0(0.0)$ & 0.32 \\
Malaise & $1(0.2)$ & $0(0.0)$ & 0.32 \\
Rash & $4(0.8)$ & $0(0.0)$ & 0.05 \\
Alopecia & $1(0.2)$ & $0(0.0)$ & 0.32 \\
Total & & $7(1.4)$ & $P<0.001$ \\
\hline
\end{tabular}

\section{Blood pressure}

Figure 2 shows that BP was reduced substantially in both treatment groups. The mean BP in the valsartan group was $158 \pm 19$ / $93 \pm 13 \mathrm{~mm} \mathrm{Hg}$ at baseline and $135 \pm 13 / 80 \pm 10 \mathrm{mmHg}$ after 3 years. The mean BP in the amlodipine group was $158 \pm 18$ / $94 \pm 13 \mathrm{~mm} \mathrm{Hg}$ at baseline and 135 $\pm 14 / 80 \pm 10 \mathrm{~mm} \mathrm{Hg}$ after 3 years. Both systolic and diastolic BPs were well controlled in both groups, and there were no significant differences between the groups in BP levels throughout the trial. The target BP (both systolic $<140 \mathrm{~mm} \mathrm{Hg}$ and diastolic BPs $<90 \mathrm{~mm} \mathrm{Hg}$ ) was achieved in 261 (51\%) patients in the valsartan group and 280 (55\%) patients in the amlodipine group.

\section{Primary endpoint}

The number of patients who reached a primary endpoint, which was a composite of all-cause death, sudden death, cerebrovascular events, cardiac events, vascular events and renal events, during the follow-up period was quite small. Primary events occurred in $21(4.1 \%)$ patients in the valsartan group and $21(4.1 \%)$ patients in the amlodipine group. There was no significant difference between the two groups in the primary composite endpoint (hazard ratio: 1.0; 95\% confidence interval (CI): $0.57-1.97 ; P=0.843$ ) (Figure 3). Table 5 compares the 


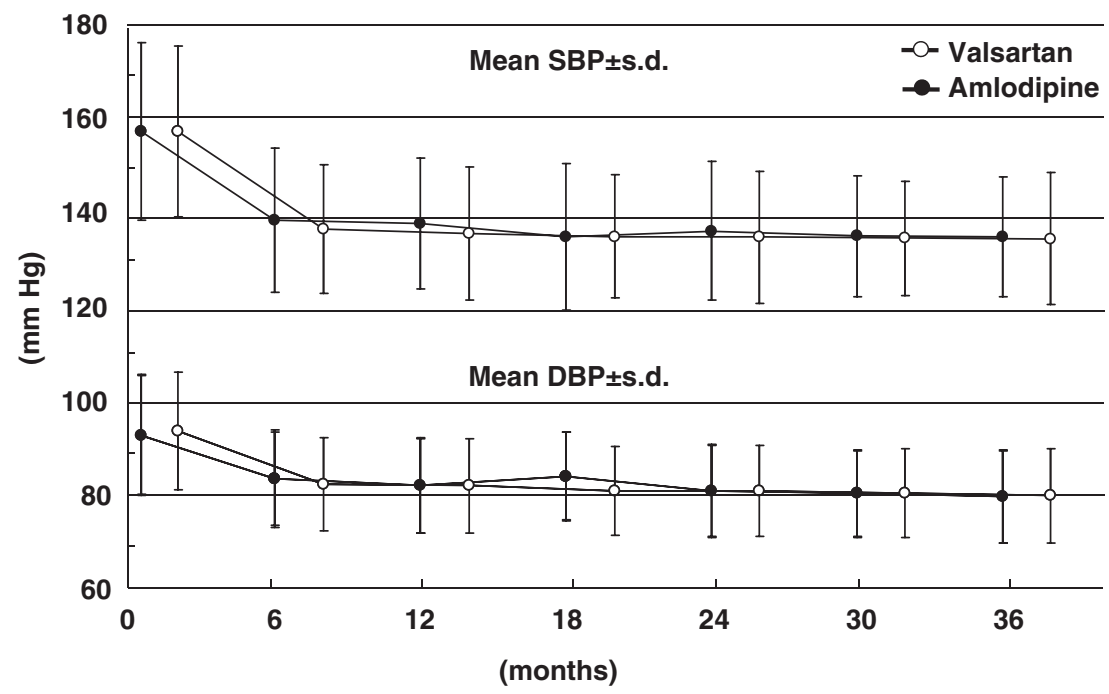

Figure 2 Changes in systolic (SBP) and diastolic BPs (DBP). SBP and DBP during the follow-up period of the trial. Data are expressed as the mean \pm s.d. $P=N S$.

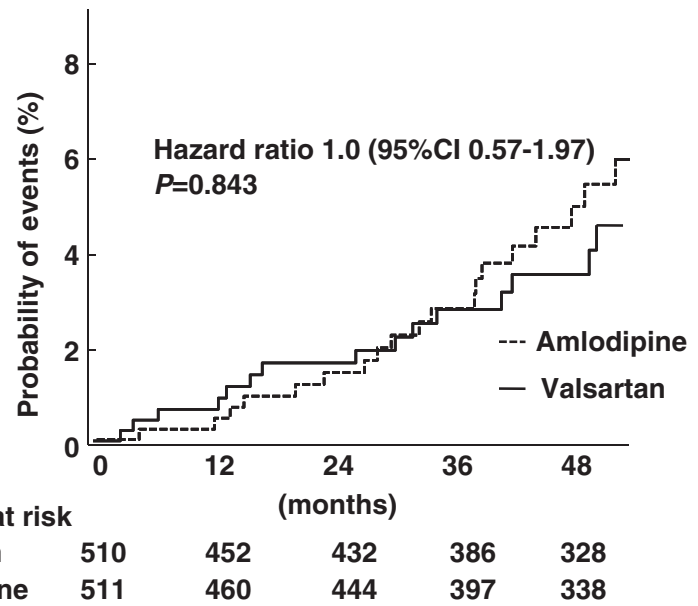

Figure 3 Kaplan-Meier curves for the primary composite endpoint.

primary endpoint for both groups. The first event for each category was counted. There was no significant difference between the two groups in the rate of each primary endpoint category. Stroke, which was the most frequent event, occurred in 10 patients $(2.0 \%)$ in the valsartan group and 10 patients $(2.0 \%)$ in the amlodipine group. Heart failure occurred in three patients $(0.6 \%)$ and in one patient $(0.2 \%)$, respectively.

\section{Secondary endpoints}

The secondary endpoints were effects on LVH, cardiac sympathetic nerve activity, blood norepinephrine level, renal function and incidence of recent-onset diabetes. We measured changes in LVMI from baseline by echocardiography to evaluate LVH. At 12 months, we observed similar decreases in LVMI in both the valsartan group and the amlodipine group. However, we observed a significant reduction in LVMI in the valsartan group compared with the amlodipine group at 36 months (valsartan group, $171.6 \mathrm{~g} \mathrm{~m}^{-2}$ at baseline and $157.8 \mathrm{~g} \mathrm{~m}^{-2}$ at 36 months; amlodipine group, $174.0 \mathrm{~g} \mathrm{~m}^{-2}$ at baseline and $171.0 \mathrm{~g} \mathrm{~m}^{-2}$ at 36 months; $P<0.05$ ) (Figure 4). Figure 5 shows the percent change in plasma norepinephrine concentration from baseline. At 36 months, we observed a significant decrease in the percent change in norepinephrine levels in the valsartan group but not in the amlodipine group $(P<0.01)$. We measured $\mathrm{H} / \mathrm{M}$ ratios by delayed imaging of ${ }^{123} \mathrm{I}-\mathrm{MIBG}$ to evaluate cardiac sympathetic nerve activity. Figure 6 shows the percent change in H/M ratio relative to baseline. At 24 months, we observed a significant increase in $\mathrm{H} / \mathrm{M}$ ratio only in the valsartan group $(P<0.0001)$. Figure 7 demonstrates the percent change in UACR relative to baseline, which indicates earlystage renal dysfunction. At 36 months, we observed a significant decrease in UACR in the valsartan group but not in the amlodipine group $(-61.3 \%$ and $34.9 \%$, respectively, $P<0.0001)$. Table 6 shows the incidence of recent-onset diabetes. During the follow-up period, the incidence of new-onset diabetes was $1.7 \%$ in the valsartan group and $3.4 \%$ in the amlodipine group. There was a trend toward less frequent recent-onset diabetes in the valsartan group, but this did not reach statistical significance.

\section{DISCUSSION}

The VART was designed to compare the ARB valsartan and the CCB amlodipine in terms of efficacy in preventing cardiovascular events in Japanese hypertensive patients. BP levels were well controlled and remained similar in the valsartan group and the amlodipine group throughout the trial. There was no significant difference between the two groups in the primary endpoints. However, in the valsartan group, significant improvements in secondary endpoints such as LVH, cardiac sympathetic nerve activity and UACR were observed.

Recent large-scale clinical trials have tested which types of antihypertensive agents have beneficial effects in reducing the risk for cardiovascular events. In the JIKEI Heart Study and the KYOTO HEART Study, the authors aimed to assess the effect of the ARB valsartan in addition to conventional treatment for high-risk hypertension in Japan. ${ }^{12,13}$ There were no significant differences in BP levels between the valsartan add-on group and the conventional treatment group in either study. However, compared with the conventional treatment group without ARBs, the valsartan add-on group included fewer patients who reached the primary endpoint, which included stroke, angina pectoris and heart failure in the JIKEI Heart Study and stroke and angina pectoris in the KYOTO HEART Study. ${ }^{12,13}$ The results of these studies demonstrate that ARBs might exert superior 
Table 5 Comparisons of the primary composite endpoint

\begin{tabular}{|c|c|c|c|c|}
\hline Endpoint & $\begin{array}{c}\text { Valsartan } \\
(\mathrm{n}=510)(\%)\end{array}$ & $\begin{array}{l}\text { Amlodipine } \\
(\mathrm{n}=511)(\%)\end{array}$ & $\begin{array}{c}\text { Hazard ratio } \\
(95 \% \mathrm{Cl})\end{array}$ & P-value \\
\hline Primary endpoint & $21(4.1)$ & $21(4.1)$ & $1.0(0.6-2.0)$ & 0.8432 \\
\hline Stroke & $10(2.0)$ & $10(2.0)$ & $1.0(0.4-2.4)$ & 0.8445 \\
\hline AMI & $2(0.4)$ & $1(0.2)$ & $2.0(0.2-22.0)$ & 0.6673 \\
\hline Angina pectoris & $2(0.4)$ & $2(0.4)$ & $1.0(0.1-0.7)$ & 0.9313 \\
\hline Transition to dialysis & $0(0.4)$ & $1(0.2)$ & & \\
\hline Doubling of serum creatinine levels & $2(0.4)$ & $3(0.6)$ & $0.7(0.1-3.9)$ & 0.8976 \\
\hline All-cause mortality & $2(0.4)$ & $3(0.6)$ & $0.7(0.1-4.0)$ & 0.8865 \\
\hline
\end{tabular}

Abbreviations: AMI, acute myocardial infarction; $\mathrm{Cl}$, confidence interval.

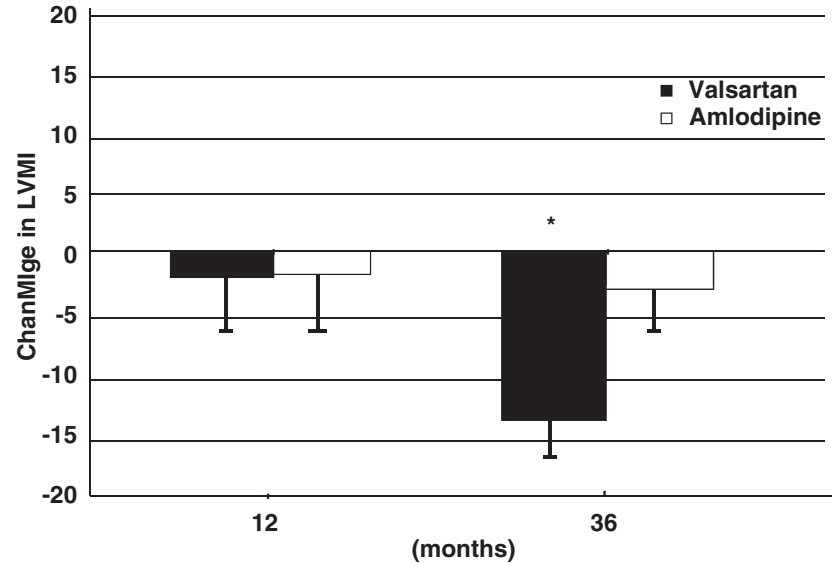

Figure 4 Changes in left ventricular mass index (LVMI) (secondary endpoint). Changes in LVMI from baseline were significantly greater in the valsartan group at 36 months. ${ }^{*} P<0.05$ compared with amlodipine group at 36 months.

cardiovascular protection as compared with other classes of antihypertensive drugs. Trials comparing the effects of ARBs and CCBs have also been performed. In the VALUE trial, the primary composite endpoint of cardiac morbidity and mortality did not differ between the valsartan group and the amlodipine group in hypertensive patients with high cardiovascular risk. ${ }^{7}$ The CASE-J trial was designed to compare the long-term effects of the ARB candesartan and the CCB amlodipine on the prevention of cardiovascular events in high-risk Japanese hypertensive patients. The trial demonstrated no statistically significant differences between the two groups in the primary cardiovascular endpoint. ${ }^{14}$ However, in these trials, the achieved BP was not equal between the two treatment groups. Furthermore, amlodipinebased therapy was significantly more effective in reducing BP, especially during the early phase of treatment. Therefore, it remains unclear whether there are differences between ARBs and CCBs in the beneficial effects on cardiovascular diseases. There are some differences between the VART and other trials in terms of the baseline characteristics of patients. In the VART, the proportions of patients with coronary artery disease, heart failure, diabetes mellitus and hyperlipidemia were $3.4,0.8,8.1$ and $27.5 \%$, respectively. The mean age of the patients in the VART was 60 years. These data suggest that the patients enrolled in the VART had fewer cardiovascular risk factors

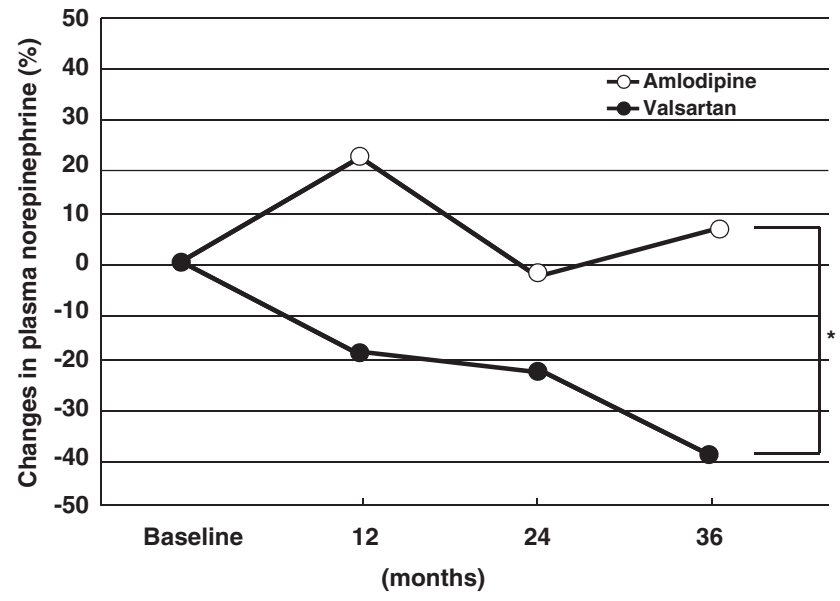

Figure 5 Changes in plasma norepinephrine (secondary endpoint). Changes in plasma norepinephrine relative to baseline were significantly decreased in the valsartan group. ${ }^{*} P<0.01$ between groups.

and were younger than those in other studies. The VART seems to be unique in its enrollment of patients at low risk for hypertension. LVH is an independent cardiovascular risk factor in the general population, especially among hypertensive patients. The Framingham Heart Study reported the relationship between an increase in left ventricular mass, as determined by echocardiography, and cardiovascular events. ${ }^{15,16} \mathrm{~A}$ greater reduction in left ventricular mass has been associated with a lower incidence of cardiovascular events in hypertensive patients. ${ }^{17,18}$ Activation of the renin-angiotensin system and an increase in the level of angiotensin II induce cardiomyocyte hypertrophy. ${ }^{19}$ Increased plasma angiotensin II has been linked to left ventricular mass independently of $\mathrm{BP}^{20}$ Therefore, ARBs seem to be promising agents that could inhibit the progression of LVH. In experimental studies, valsartan showed better effects on LVH than amlodipine; these effects were mediated by the reduction of reactive oxygen species. ${ }^{21}$

Cardiac sympathetic nerve activity can be assessed through the use of ${ }^{123} \mathrm{I}-\mathrm{MIBG}$, an analog of norepinephrine. In particular, the H/M ratio on delayed imaging of ${ }^{123}$ I-MIBG is used to evaluate cardiac sympathetic nerve activity in various diseases such as heart failure, diabetes mellitus and hypertension. It has been reported that heart failure patients with decreased $\mathrm{H} / \mathrm{M}$ ratios upon delayed imaging of ${ }^{123} \mathrm{I}-\mathrm{MIBG}$ have worse prognoses than those with normal $\mathrm{H} / \mathrm{M}$ 


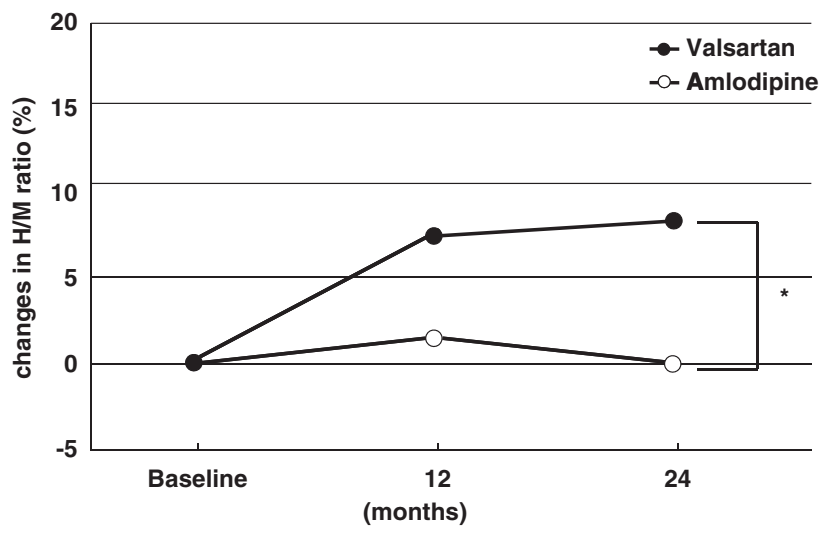

Figure 6 Changes in the heart to mediastinum (H/M) ratios (123/metaiodobenzylguanidine (123/-MIBG)) (secondary endpoint). H/M ratios by delayed imaging were significantly improved in the valsartan group. ${ }^{*} P<0.0001$ between groups.

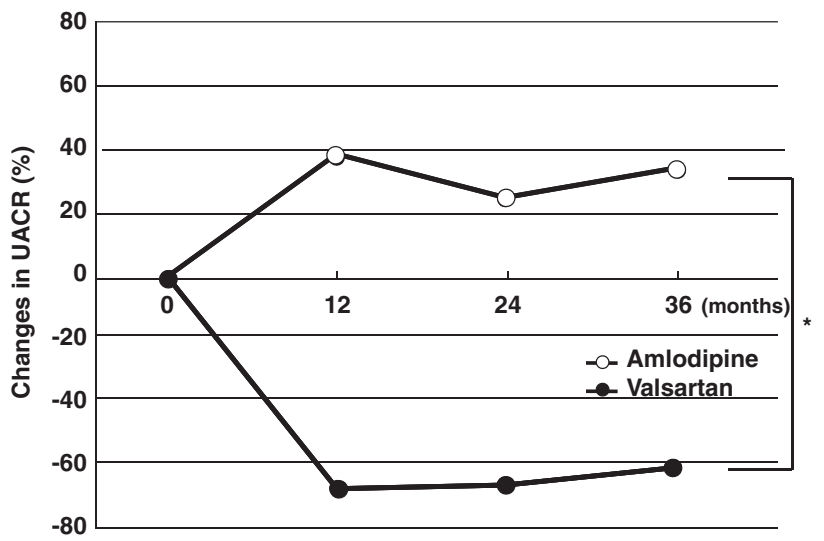

Figure 7 Changes in urinary albumin to creatinine ratio (UACR) (secondary endpoint). Changes in UACR relative to baseline were significantly decreased in the valsartan group. ${ }^{*} P<0.0001$ between groups.

Table 6 New diagnosis of diabetes (secondary endpoint)

\begin{tabular}{|c|c|c|c|c|}
\hline & \multicolumn{2}{|c|}{ Diabetes at baseline } & \multirow{2}{*}{$\begin{array}{c}\text { New-onset } \\
\text { diabetes mellitus }\end{array}$} & \multirow{2}{*}{$\begin{array}{l}\text { Odds ratio } \\
(95 \% \mathrm{Cl})\end{array}$} \\
\hline & + & - & & \\
\hline Valsartan & 37 & 473 & $8 / 473(1.7 \%)$ & \\
\hline Amlodipine & 46 & 465 & $16 / 465(3.4 \%)$ & $0.47(0.20-1.11)$ \\
\hline
\end{tabular}

Abbreviation: $\mathrm{Cl}$, confidence interval.

ratios. ${ }^{22}$ The H/M ratio was significantly lower in the hypertensive patients than in the normotensive and borderline hypertensive patients. ${ }^{23}$ In addition to mechanical stress, increased sympathetic nerve activity has been proposed as one of the important factors in the development and progression of LVH. Thus, MIBG cardiac imaging might be useful in identifying hypertensive patients at risk of developing LVH in the early stages of the development of hypertension. In our study, the H/M ratio was significantly improved at 24 months in the valsartan-treated group but not in the amlodipine-treated group. Plasma norepinephrine levels were significantly reduced only in the valsartan group. Another study also reported that amlodipine did not affect plasma norepinephrine levels or renin activity. ${ }^{24}$ ARBs are known to reduce central sympathetic nerve activity and enhance the sympathoinhibitory response to baroreceptor stimulation. Our results suggest that valsartan reduces cardiac sympathetic nerve activity and plasma norepinephrine levels by blocking the reninangiotensin system.

Reduction of urinary albumin induces a decrease in cardiovascular events in patients with hypertension and type 2 diabetes. ${ }^{25,26}$ Epidemiological data show that high levels of UACR are associated with increased cardiovascular mortality. ${ }^{27-29}$ In the subanalysis of the Losartan Intervention For End-point reduction (LIFE) study and the Prevention of Renal and Vascular End-Stage Disease (PREVEND) study, UACR was reported to be a predictor of all causes of mortality in the general population. ${ }^{25,30}$ Increased UACR predicts high risk for cardiovascular morbidity and mortality among hypertensive patients with LVH. ${ }^{31}$ Furthermore, inhibition of the renin-angiotensin system has been shown to normalize estimated glomerular hydraulic pressure and glomerular permeability properties, as well as restore the charge selectivity of the glomerular membrane. ${ }^{32-35}$ In the MicroAlbuminuria Reduction With VALsartan (MARVAL) study, for the same degree of BP reduction, valsartan lowered UACR more effectively than amlodipine in patients with type 2 diabetes and microalbuminuria. ${ }^{36}$ The Shiga Microalbuminuria Reduction Trial (SMART) also showed that after 24 weeks of treatment, microalbuminuria decreased $36 \%$ in the valsartan group and increased $30 \%$ in the amlodipine group. ${ }^{37}$

In this study, we enrolled low-risk patients with mild to moderate hypertension. To date, many trials have been designed to evaluate the effects of antihypertensive agents on high-risk hypertensive patients. Although it is important to find the optimal treatment for high-risk hypertensive patients, it is also necessary to examine the appropriate treatment for low-risk patients with mild to moderate hypertension. However, there are few studies that have investigated the effects of the treatment on those patients. In the VART, the proportion of the patients treated with valsartan or amlodipine monotherapy was large, which allowed a valid comparison of valsartan and amlodipine. Our trial has limitations. As the number of the enrolled patients was smaller than first planned, it is possible that the follow-up period was too short to demonstrate statistical significance. In conclusion, valsartan treatment did not differ significantly from the amlodipine treatment among patients with similar BPs, as measured by the number of patients who reached a primary endpoint. Nonetheless, valsartan showed beneficial effects on heart and kidney function in Japanese hypertensive patients.

\section{CONFLICT OF INTEREST}

The authors declare no conflict of interest.

\section{ACKNOWLEDGEMENTS}

We thank all of the participants, physicians, medical staff and other contributors to the VART. Details of the members of the VART are as follows: representative, Issei Komuro; steering committee, Hiroyuki Takano, Yoichi Kuwabara, Satoshi Shindo, Keiko Nakayama, Miwa Fujita, Hiroya Narumi and Hiroshi Mizuma; data and safety monitoring board, Toshiharu Himi (Kimitsu Chuo Hospital), Akira Aouda (Chiba Cardiovascular Center) and Toru Takami (National Chiba Hospital); event evaluation committee, Osahiro Takahashi (Chiba Aoba Municipal Hospital), Hiroyuki Niwayama (Funabashi Social Insurance Hospital) and Yukinori Kohno (Chiba Social Insurance Hospital); statistical analysis, Nobuo Shirahashi (Clinical Epidemiology, Osaka City University Graduate School). 
1 Cohn JN, Tognoni G. A randomized trial of the angiotensin-receptor blocker valsartan in chronic heart failure. N Engl J Med 2001; 345: 1667-1675.

2 Lindholm LH, Ibsen $H$, Dahlof B, Devereux RB, Beevers G, de Faire U, Fyhrquist F, Julius S, Kjeldsen SE, Kristiansson K, Lederballe-Pedersen O, Nieminen MS, Omvik P, Oparil S, Wedel H, Aurup P, Edelman J, Snapinn S. Cardiovascular morbidity and mortality in patients with diabetes in the Losartan Intervention For Endpoint reduction in hypertension study (LIFE): a randomised trial against atenolol. Lancet 2002; 359: 1004-1010.

3 Pfeffer MA, Swedberg K, Granger CB, Held P, McMurray JJ, Michelson EL, Olofsson B, Ostergren J, Yusuf S, Pocock S. Effects of candesartan on mortality and morbidity in patients with chronic heart failure: the CHARM-Overall programme. Lancet 2003; 362 . 759-766.

4 McMurray JJ, Ostergren J, Swedberg K, Granger CB, Held P, Michelson EL, Olofsson B, Yusuf S, Pfeffer MA. Effects of candesartan in patients with chronic heart failure and reduced left-ventricular systolic function taking angiotensin-converting-enzyme inhibitors: the CHARM-Added trial. Lancet 2003; 362: 767-771.

5 Granger CB, McMurray JJ, Yusuf S, Held P, Michelson EL, Olofsson B, Ostergren J, Pfeffer MA, Swedberg K. Effects of candesartan in patients with chronic heart failure and reduced left-ventricular systolic function intolerant to angiotensinconverting-enzyme inhibitors: the CHARM-Alternative trial. Lancet 2003; 362: 772-776.

6 Yusuf S, Pfeffer MA, Swedberg K, Granger CB, Held P, McMurray JJ, Michelson EL, Olofsson B, Ostergren J. Effects of candesartan in patients with chronic heart failure and preserved left-ventricular ejection fraction: the CHARM-Preserved Trial. Lancet 2003; 362: 777-781.

7 Weber MA, Julius S, Kjeldsen SE, Brunner HR, Ekman S, Hansson L, Hua T, Laragh JH, McInnes GT, Mitchell L, Plat F, Schork MA, Smith B, Zanchetti A. Blood pressure dependent and independent effects of antihypertensive treatment on clinical events in the VALUE Trial. Lancet 2004; 363: 2049-2051.

8 Nakayama K, Kuwabara Y, Daimon M, Shindo S, Fujita M, Narumi H, Mizuma H, Komuro I. Valsartan Amlodipine Randomized Trial (VART): design, methods, and preliminary results. Hypertens Res 2008; 31: 21-28.

9 Palmieri V, Dahlöf B, DeQuattro V, Sharpe N, Bella JN, de Simone G, Paranicas M, Fishman D, Devereux RB. Reliability of echocardiographic assessment of left ventricular structure and function: the PRESERVE study. Prospective randomized study evaluating regression of ventricular enlargement. J Am Coll Cardiol 1999; 34: 1625-1632.

10 Crawford MH, Souchek J, Oprian CA, Miller DC, Rahimtoola S, Giacomini JC, Sethi G, Hammermeister KE. Determinants of survival and left ventricular performance after mitral valve replacement. Department of Veterans Affairs Cooperative Study on Valvular Heart Disease. Circulation 1990; 81: 1173-1181.

11 Hansson L, Lindholm LH, Ekbom T, Dahl of B, Lanke J, Schersten B, Wester PO, Hedner $\mathrm{T}$, de Faire U. Randomised trial of old and new antihypertensive drugs in elderly patients: cardiovascular mortality and morbidity the Swedish Trial in Old Patients with Hypertension-2 study. Lancet 1999; 354: 1751-1756.

12 Mochizuki S, Dahlof B, Shimizu M, Ikewaki K, Yoshikawa M, Taniguchi I, Ohta M, Yamada T, Ogawa K, Kanae K, Kawai M, Seki S, Okazaki F, Taniguchi M, Yoshida S, Tajima N. Valsartan in a Japanese population with hypertension and other cardiovascular disease (Jikei Heart Study): a randomised, open-label, blinded endpoint morbidity-mortality study. Lancet 2007; 369: 1431-1439.

13 Sawada T, Yamada H, Dahlof B, Matsubara H. Effects of valsartan on morbidity and mortality in uncontrolled hypertensive patients with high cardiovascular risks: KYOTO HEART Study. Eur Heart J 2009; 30: 2461-2469.

14 Ogihara T, Nakao K, Fukui T, Fukiyama K, Ueshima K, Oba K, Sato T, Saruta T. Effects of candesartan compared with amlodipine in hypertensive patients with high cardiovascular risks: candesartan antihypertensive survival evaluation in Japan trial. Hypertension 2008; 51: 393-398.

15 Levy D, Garrison RJ, Savage DD, Kannel WB, Castelli WP. Prognostic implications of echocardiographically determined left ventricular mass in the Framingham Heart Study. N Engl J Med 1990; 322: 1561-1566.

16 Bikkina M, Levy D, Evans JC, Larson MG, Benjamin EJ, Wolf PA, Castelli WP. Left ventricular mass and risk of stroke in an elderly cohort. The Framingham Heart Study. JAMA 1994; 272: 33-36.

17 Dahlof B, Devereux RB, Kjeldsen SE, Julius S, Beevers G, de Faire U, Fyhrquist F, Ibsen $\mathrm{H}$, Kristiansson $\mathrm{K}$, Lederballe-Pedersen $\mathrm{O}$, Lindholm LH, Nieminen MS, Omvik $\mathrm{P}$ Oparil S, Wedel H. Cardiovascular morbidity and mortality in the Losartan Intervention For Endpoint reduction in hypertension study (LIFE): a randomised trial against atenolol. Lancet 2002; 359: 995-1003.

18 Okin PM, Devereux RB, Gerdts E, Snapinn SM, Harris KE, Jern S, Kjeldsen SE, Julius S, Edelman JM, Lindholm LH, Dahlof B. Impact of diabetes mellitus on regression of electrocardiographic left ventricular hypertrophy and the prediction of outcome during antihypertensive therapy: the Losartan Intervention For Endpoint (LIFE) Reduction in Hypertension Study. Circulation 2006; 113: 1588-1596.

19 Nagano M, Higaki J, Mikami H, Nakamaru M, Higashimori K, Katahira K, Tabuchi Y, Moriguchi A, Nakamura F, Ogihara T. Converting enzyme inhibitors regressed cardiac hypertrophy and reduced tissue angiotensin II in spontaneously hypertensive rats. J Hypertens 1991; 9: 595-599.

20 Schmieder RE, Langenfeld MR, Friedrich A, Schobel HP, Gatzka CD, Weihprecht H. Angiotensin II related to sodium excretion modulates left ventricular structure in human essential hypertension. Circulation 1996; 94: 1304-1309.

21 Yasunari K, Maeda K, Watanabe T, Nakamura M, Yoshikawa J, Asada A. Comparative effects of valsartan versus amlodipine on left ventricular mass and reactive oxygen species formation by monocytes in hypertensive patients with left ventricular hypertrophy. J Am Coll Cardiol 2004; 43: 2116-2123.

22 Verberne HJ, Brewster LM, Somsen GA, van Eck-Smit BL. Prognostic value of myocardial 123I-metaiodobenzylguanidine (MIBG) parameters in patients with heart failure: a systematic review. Eur Heart J 2008; 29: 1147-1159.

23 Sakata K, Shirotani M, Yoshida H, Kurata C. Cardiac sympathetic nervous system in early essential hypertension assessed by 123I-MIBG. J Nucl Med 1999; 40: 6-11.

24 Sakata K, Shirotani M, Yoshida H, Nawada R, Obayashi K, Togi K, Miho N. Effects of amlodipine and cilnidipine on cardiac sympathetic nervous system and neurohormonal status in essential hypertension. Hypertension 1999. 33. 1447-1452.

25 Ibsen H, Olsen MH, Wachtell K, Borch-Johnsen K, Lindholm LH, Mogensen CE, Dahlof B, Devereux RB, de Faire U, Fyhrquist F, Julius S, Kjeldsen SE, Lederballe-Pedersen O, Nieminen MS, Omvik P, Oparil S, Wan Y. Reduction in albuminuria translates to reduction in cardiovascular events in hypertensive patients: losartan intervention for endpoint reduction in hypertension study. Hypertension 2005; 45: 198-202.

26 Gaede P, Vedel P, Larsen N, Jensen GV, Parving HH, Pedersen O. Multifactorial intervention and cardiovascular disease in patients with type 2 diabetes. $N$ Engl J Med 2003; 348: 383-393.

27 Jager A, Kostense PJ, Ruhe HG, Heine RJ, Nijpels G, Dekker JM, Bouter LM, Stehouwer $\mathrm{CD}$. Microalbuminuria and peripheral arterial disease are independent predictors of cardiovascular and all-cause mortality, especially among hypertensive subjects: fiveyear follow-up of the Hoorn Study. Arterioscler Thromb Vasc Biol 1999; 19: 617-624.

28 Gerstein HC, Mann JF, Pogue J, Dinneen SF, Halle JP, Hoogwerf B, Joyce C, Rashkow A, Young J, Zinman B, Yusuf S. Prevalence and determinants of microalbuminuria in highrisk diabetic and nondiabetic patients in the Heart Outcomes Prevention Evaluation Study. The HOPE Study Investigators. Diabetes Care 2000; 23(Suppl 2): B35-B39.

29 Roest M, Banga JD, Janssen WM, Grobbee DE, Sixma JJ, de Jong PE, de Zeeuw D, van Der Schouw YT. Excessive urinary albumin levels are associated with future cardiovascular mortality in postmenopausal women. Circulation 2001; 103: 3057-3061.

30 Hillege HL, Fidler V, Diercks GF, van Gilst WH, de Zeeuw D, van Veldhuisen DJ, Gans $R O$, Janssen WM, Grobbee $D E$, de Jong $P E$. Urinary albumin excretion predicts cardiovascular and noncardiovascular mortality in general population. Circulation 2002; 106: 1777-1782.

31 Wachtell K, Ibsen H, Olsen MH, Borch-Johnsen K, Lindholm LH, Mogensen CE, Dahlof B, Devereux RB, Beevers G, de Faire U, Fyhrquist F, Julius S, Kjeldsen SE, Kristianson K, Lederballe-Pedersen O, Nieminen MS, Okin PM, Omvik P, Oparil S, Wedel H, Snapinn SM, Aurup P. Albuminuria and cardiovascular risk in hypertensive patients with left ventricular hypertrophy: the LIFE study. Ann Intern Med 2003; 139: 901-906.

32 Andersen S, Blouch K, Bialek J, Deckert M, Parving HH, Myers BD. Glomerular permselectivity in early stages of overt diabetic nephropathy. Kidney Int 2000; 58: 2129-2137.

33 Trevisan R, Tiengo A. Effect of low-dose ramipril on microalbuminuria in normotensive or mild hypertensive non-insulin-dependent diabetic patients. North-East Italy Microalbuminuria Study Group. Am J Hypertens 1995; 8: 876-883.

34 Imanishi M, Yoshioka K, Konishi Y, Okumura M, Okada N, Sato T, Tanaka S, Fujii S, Kimura G. Glomerular hypertension as one cause of albuminuria in type II diabetic patients. Diabetologia 1999; 42: 999-1005.

35 Langham RG, Kelly DJ, Cox AJ, Thomson NM, Holthofer H, Zaoui P, Pinel N, Cordonnier DJ, Gilbert RE. Proteinuria and the expression of the podocyte slit diaphragm protein, nephrin, in diabetic nephropathy: effects of angiotensin converting enzyme inhibition. Diabetologia 2002; 45: 1572-1576.

36 Viberti G, Wheeldon NM. Microalbuminuria reduction with valsartan in patients with type 2 diabetes mellitus: a blood pressure-independent effect. Circulation 2002; 106: 672-678.

37 Uzu T, Sawaguchi M, Maegawa H, Kashiwagi A. Impact of renin-angiotensin system inhibition on microalbuminuria in type 2 diabetes: a post hoc analysis of the Shiga Microalbuminuria Reduction Trial (SMART). Hypertens Res 2008; 31: 1171-1176.

\section{APPENDIX}

Members of the VART are the following:

Masayuki Asakawa, Masao Daimon, Koichi Doi, Yoshihide Fujimoto, Miwa Fujita, Takao Furukawa, Masanobu Furuya, Rei Hasegawa, Naotake Hashimoto, Tomoyuki Hattori, Yasuyoshi Hijikata, Kiyoshi Hibiya, Toshiharu Himi, Susumu Higaki, Aizan Hirai, Yasuaki Hosaka, Tetsuo Hoshino, Takashi Ichikawa, Yoshihiro Iijima, Tamekazu Ikegami, Hirofumi Imai, Hitoshi Imai, Kunihiko Isoyama, Kenzo Ito, Yoshitaka Iwama, Koji Iwabe, Tsuneo Kabe, Takumi Kajikawa, Tomoji Kasaya, Mituo Kataoka, Natsuki Kiuchi, Yasuharu Kodama, Hirohito Koizumi, Tomomi Koizumi, Yuichiro Koshibu, Masaaki Kozu, Yumiko Kozai, Akihito Kuroda, Takashi Kurono, Shinichi Kuribayashi, Yoichi Kuwabara, Fumiaki Maeda, Yuji Matsudo, Taizo Matsuishi, Heita Matsunaga, Yoko Mikami, Akira Minato, Osamu Mitsuhashi, Masayoshi Miura, Kimihiko Mizuguchi, Hiroshi Mizuma, Kyoichi Mizuno, Takeshi Mizuno, Hiroshi Murayama, Shinichiro Mitsunaga, 
Toshio Nagai, Mikio Nagashima, Koichi Nakajima, Masato Nakamura, Takashi Nakazato, Keiko Nakayama, Shizuko Narita, Kenji Ogura, Kazuo Ohie, Syunpei Ohkubo, Tetsuo Ohkubo, Kyoko Okuyama, Yoko Pearce, Makoto Sakakibara, Tetsuaki Sakaguchi, Naoki Saigusa, Fumio Sakamoto, Hitoshi Sato, Isao Sato, Teizaburou Sekiya, Masahiro Seko, Nobuaki Shikama, Takeshi Shikama, Issei Shimada, Masuo Shina, Satoshi Shindo, Haruyuki Shinozaki, Hirokazu Shiraishi, Teruo Sugibayashi, Takehiko Sugiyama,
Masashi Takahashi, Hiroyuki Takano, Noriaki Takahashi, Ken Takeda, Taichi Takizawa, Madoka Tanaka, Kiyomi Teramoto, Masashi Terashima, Yasuyuki Tomita, Tomohiko Toyoda, Tetsuya Toyozaki, Yoshiaki Tsukamoto, Takako Umimura, Fusayo Wagai, Keisuke Wakisaka, Shigeru Watanabe, Toshio Yajima, Masato Yamanouchi, Katsumi Yamada, Masahiko Yamada, Zenju Yamada, Masashi Yamamoto, Tsutomu Yokosuka, Hideo Yoshida and Katsuya Yoshida. 


\section{Retraction: Effects of valsartan and amlodipine on cardiorenal protection in Japanese hypertensive patients: the Valsartan Amlodipine Randomized Trial}

Hiroya Narumi, Hiroyuki Takano, Satoshi Shindo, Miwa Fujita, Hiroshi Mizuma, Yoichi Kuwabara and Issei Komuro on behalf of the VART Investigators

Hypertension Research (2017) 40, 103; doi:10.1038/hr.2016.144; published online 3 November 2016

Retraction to: Hypertension Research (2011) 34, 62-69; doi:10.1038/ hr.2010.186

The authors have indicated to the journal that this paper should be retracted as it contains honest errors, which cannot be corrected accurately by the existing data. After careful consideration, Hypertension Research editorial committee formally retracts this paper with agreement of the authors.
This article has published corrigenda in Volume 34, Issue 1, page 152, doi:10.1038/hr.2010.219 and Volume 36, Issue 7, page 655, doi:10.1038/hr.2013.54. These corrigenda are retracted together with the Original Article. 